\section{PL.80 ELECTIVE C-SECTIONS: A FUTURE DAY SURGERY CASE?}

doi:10.1136/archdischild-2013-303966.262

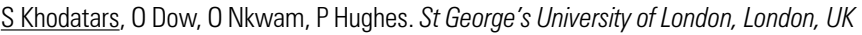

The number of women opting for elective caesarean sections has steadily increased within the last few years. Our aim is to assess whether the Enhanced Recovery Programme (ERP), a national programme aiming to improve the outcome of elective caesareans by active patient participation, could lead to quicker recoveries and earlier discharges whilst maintaining the best standard of care.

Method A paper-based questionnaire was distributed to the women opting for an Elective Caesarean from 03/09/2012 to 20/11/2012.

The questionnaire aimed to assess the ERP by questioning patients' timing of eating, drinking and mobilisation post-operatively, attendance to the STOP discharge meeting, time of catheter removal and discharge time.

Results

- The majority had their first meal within 2 hours, or 4-6 hours, with the rest being $6+$ hours.

- Most of the women had their catheter removed on time.

- The majority were unaware of the STOP discharge meeting and so did not attend.

- The majority were discharged on the $2^{\text {nd }}$ day.

\section{Conclusion}

- The study revealed that only about a quarter of patients are able to go home on the $1^{\text {st }}$ day after the Caesarean, while more left on the $2^{\text {nd }}$ day.

- Only very few had their evening meal whilst seated and only a third attended the STOP Discharge meeting. Both of these should be aimed to be increased under guidance of the ERP.

Based on these results, the study shows a need for further ERP adherence to assist recovery of women following a Caesarean section.

\section{PL.81 CAESAREAN SECTION AT THE OEHKL: 10 YEARS ON FROM "SENTINEL", WHERE ARE WE?}

doi:10.1136/archdischild-2013-303966.263

\section{T Mokate, I Anayath. The Queen Elizabeth Hospital, Kings Lynn, UK}

Objective At the time of the National Sentinel Caesarean Section Audit the caesarean section rate (CSR) was rising by $1 \%$ per year. This audit aims to compare our current practise with that described in the Sentinel audit.

Design Retrospective Study.

Setting The Queen Elizabeth Hospital Kings Lynn.

Population Caesarean sections from three months of 2011-12.

Methods Case note review.

Main outcomes The primary outcomes were the caesarean section rate (CSR), the indications, appropriateness of the indication, and whether fetal blood sampling, external cephalic version (ECV), vaginal birth after caesarean (VBAC) were offered

Results The CSR was unchanged at 22\% (18\% "Sentinel"), forceps $7 \%(2.9-5.7 \%)$ and Ventouse 5\% (5.7-9.7\%) with 1:1 midwifery care in $92 \%$ of deliveries. The primary CSR was $66 \%$. The electives were $34 \%(37 \%)$ and emergencies $66 \%$ (63\%).

Only $4.2 \%$ of indications were debatable and in Grade 2 (G2) and 3 (G3) caesareans. The G2 caesareans indications were $30.7 \%$ for abnormal cardiotocograph and $53.5 \%$ for failure to progress (FTP). Only $6.7 \%$ had fetal blood sampling (FBS). Elective caesarean indications included, declined vaginal birth after one caesarean (32.1\%), vaginal birth after two caesareans not offered (18.9\%) and declined external cephalic version (13.2\%).

Conclusions The CRS has remained static over the last decade despite occasional peaks. The majority of caesareans during these peaks were justified. The CSR could be improved by reducing the primary indications by increasing the use of FBS and better management of failure to progress, and secondary indications by improved counselling for VBAC and ECV.

\section{PL.82 AN AUDIT OF COMPLIANCE WITH CURRENT GUIDELINES ON THE MANAGEMENT OF THIRD AND FOURTH DEGREE TEARS IN THE ROTUNDA HOSPITAL}

doi:10.1136/archdischild-2013-303966.264

A Doyle, S Cooley, K O' Halloran, M Whelan, M Eogan. Rotunda Hospital, Dublin, Ireland

$3^{\text {rd }}$ and $4^{\text {th }}$ degree tears occur in $1 \%$ of vaginal deliveries. In the Rotunda the rate in the first six months of 2012 was increased at $3 \%$. The aim of this audit was to assess compliance with current Rotunda guidelines and where non-compliance was identified assess if complications arose as a result.

A retrospective chart review of all third and fourth degree tears was performed. There were 51 cases during this time period and 47 charts were available for review. The comparison standard was the Rotunda Hospitals "Guidelines for Management of Episiotomy and Repair of Perineal Trauma" Sept 2010.

There were 51 cases in total. $45 \%$ were following Spontaneous vertex delivery, $27 \%$ following ventouse delivery, $14 \%$ following combination of ventouse and forceps and 14\% forceps alone. 100\% were repaired under regional anaesthesia. Only $66 \%$ received the correct dose and duration of antibiotics. $95 \%$ received laxatives post delivery with only $51 \%$ received appropriate non-opiate analgesia. $44.6 \%$ of patients were reviewed by senior staff and $81 \%$ received physiotherapy. $87 \%$ were followed up in the perineal clinic.

Review of current perineal repair form should be performed to include headings more specific to third/fourth degree tears. A sticker highlighting that the patient has had a third/fourth degree tear should be placed on the front of drug Kardex. This may help avoid prescription of opiate analgesia. All women receive an information leaflet on discharge. Women should have senior staff review day 1 postpartum. It should be re-audited in six months.

\section{PL.83 TRENDS IN CAESAREAN SECTION IN THE EAST OF SCOTLAND}

doi:10.1136/archdischild-2013-303966.265

V Laxman, V Balakumar, A Nicoll. Ninewells Hospital,Dundee, Dundee, UK

Aims In Tayside in 2012 we observed an increase in the rate of caesarean section (CS). Our aim was to determine the cause of this and to develop strategies that might prevent further increase.

Methods A prospective longitudinal audit was performed. All women who required CS in July 2012 were included. Robson's classification (RC) was used to categorise women. Women who had CS in July 2007 were identified using the local maternity database (Torex Protos Evolution) and these were also categorised for comparison.

Results In $200777 / 353$ (21.8\%) and in 2012 86/377 (22.8\%) required CS $(p=N / S)$. For both groups the most frequent category was RC5 (multiparous, $\geq 37$ weeks, previous CS). In 2007 27/77 (35\%) were RC5 and in 2012 35/86 (40\%) were RC5. In 2007 the next category was RC10 ( $\leq 36$ weeks) (12/77, 15.5\%). However in 2012 this accounted for $3 / 86(3 \%)(p=0.03)$. In 2012 the second largest group was RC2 (primiparous induced/CS prior to labour). This had increased from $7 / 77$ (9\%) in 2007 to $19 / 86(22 \%)$ in 2012 ( $p=0.03)$. 